\title{
Tapping into the emotions of the wine consumer through storytelling: A case study
}

\author{
V. Woldarsky \\ Doctoral Programme in Tourism and Leisure, Universitat Rovira i Virgili, Tarragona, Spain
}

\begin{abstract}
Stories are powerful and they have taken on a new dimension in the marketing world. Using storytelling or narrative as a communication technique can be an effective tool for persuasion, as well as way to connect with the consumer on shared values. But a simple narrative is not enough. It is in the evocation of emotions that the storytelling carries its power. The research presented in this paper shows that emotions are powerful: as a way to build trust, create closeness, hold attention and transport the reader/listener to another world - all of which can result in certain behavioral responses. This paper focuses on understanding storytelling in tourism context, specifically in wine tourism. Wine tourism provides the producer the chance to tell their story and build a special relationship. The winery experience opens up greater possibilities to stimulate good feelings for the visitor. Coupled with a compelling narrative that takes the wine tourist on a physical and emotional journey, the ability to sell the brand becomes possible. The case study presented in this paper is Quinta do Vallado, in the Douro Valley, Portugal. It will show how the script that was used to communicate with the visitor was transformed into a compelling narrative.
\end{abstract}

Wine publications and trade magazines abound with articles discussing wine communication and marketing in a world where there is a plethora of beverage choices. While there has been a global increase in wine consumption in the past five years [1], there are many changes in consumption habits that are creating a huge challenge for the wine industry. Baby Boomers no longer represent a large portion of wine drinkers, and younger consumers, such as Generation Y or Millennials (those born between 1980 to the mid-90s) are choosing to drink wine less often, but are drinking higher value wines for special occasions or on-premise [2]. There has also been a decrease in consumption in wine-producing countries, particularly Old World producers [3]. Mature markets, such as the United Kingdom, have also seen a shift in consumption, with less wine being consumed but higher sales in spirits [4]. All of these changes have created confusion on how to proceed in marketing and communication. How can a brand have a greater connection with the consumer? And how to increase brand loyalty and maintain engagement?

In order to connect with the consumer, a new, unique and fresh approach to communicating with the consumer is required. The repeated phrases, "Facts tell, stories sell" and "No tale, no sale" [5] indicate that storytelling has become increasingly important in marketing. Further, marketing research shows that engaging the consumer through emotion is more effective than traditional persuasion techniques. But, why has storytelling become so important now? What is its relevance to wine? And how to apply storytelling in practical way?

This article delves into storytelling and will attempt to show how it can be an effective communication tool not only for persuasion, but as way to connect with the consumer on shared values. To illustrate storytelling and its application, the case study of Quinta do Vallado, a historic winery in the Douro Valley, Portugal will be discussed. The purpose of presenting this case study is to deconstruct the story telling process and show the creation process of the new script that will be used during the winery tour. The present study gathers knowledge from various fields. The literature review will focus on consumer behavior, wine marketing, hedonic consumption, wine tourism, narrative and the neuroscience underlying emotions. This conceptual foundation will lead to storytelling, with examination of its importance and construction.

Please note that in this paper, the word "consumer" is used interchangeably with "visitor" as visitors can represent consumers of wine and consumers of experiences.

\section{Literature review}

\subsection{Wine marketing and consumer purchasing behavior}

Marketing strategy typically relies on consumer knowledge of a product or service and thus, segment according to targeted group. However, consumer wine knowledge is not always easily understood. Vigar-Ellis et al. (2015) claim that wine knowledge is threefold: it can be objective - what the consumer actually knows about the product, subjective - what they believe they know, and experiential-the knowledge derived from the number of times experiencing the product. In an online study designed to measure wine consumers product knowledge in the United States, it was found that most consumers have high subjective knowledge. That is, the majority of wine consumers tend to overestimate what they know. Because of this, consumer will often feel dissatisfied or disappointed with their selected wine [6]. 
To minimize the perceived risk of purchasing the wrong wine, consumers will often use various strategies when it comes to purchasing [7]. These include selecting based on intrinsic attributes of wine such as color and taste through tasting notes, or extrinsic aspects such as grape variety, vintage, origin, and alcohol content. Consumers can also be influenced by awards and medals, which may serve as guarantee of quality. Overall, however, appellation or guaranteed region of origin and past experiences have become much more important in decision-making. In addition, brands play a decisive role in consumer wine choice. Some studies indicate that brands have the strongest importance for consumers. However, it has also been noted that the impact and influence of brands is more significant for experienced wine consumers than for novice drinkers [8].

In the same fashion, wine communication has also tended to focus on the extrinsic attributes or sensory properties of wine. This is most evident at a wine fair or event, where an attendee can walk from one stand to another and hear very similar descriptions from one producer to another. Typically, wine is broken down into its various components, such as alcohol percentage, acidity, $\mathrm{pH}$ levels, or by its creation process, such as maceration time, fermentation period and processes, aging time, barrel type and porosity, etc. In another setting, such as a leisure setting at a restaurant or wine bar, customers have access to a very knowledgeable wine professional, the sommelier. The terminology used to taste wine, such as the descriptions for color, body, acidity and finish are easily understood by trade and professionals, but not always easily understood by consumers. While these extrinsic and intrinsic attributes of wine are important in consumer decision-making, when confronted with an overwhelming number of wines and brands, such as in the supermarket or wine shop, consumers often feel insecure and unconfident [9]. Furthermore, the use of "hard facts" of wine as a communication technique creates a gap between the product and the consumer.

\subsection{Hedonic consumption experiences}

It has been long assumed that consumers were rational beings and that their purchasing choices were based on functional and utilitarian needs. However, the research done by Hollbrock and Hirschman (1982) on consumer behavior opened a new view of the consumer; not always rational, the consumer may make product choices based on emotional needs and desires, such as seeking fun, pleasure, and sensorial stimulation. Hedonic consumption, as opposed to utilitarian consumption, consists of "facets of consumer behavior that relate to the multisensory, fantasy and emotive aspects of product usage experience" [10].

Both wine and tourism fall under hedonic consumption, the first as a product, the latter as a service and experience. Wine is not consumed for survival or sustenance. It is a cultural product that has touched many societies deeply, and continues to be part of the collective experience for many wine-producing countries. It is also a luxury product and can be seen as a status symbol [11]. Despite all these symbolic meanings, it is mainly consumed for pleasure and enjoyment and it has a way of captivating individuals, either because of the fascination of how it is made or because of the images, history and heritage associated with it. Wine can provoke emotional impressions that can have lasting effects and can work to create memories long after the tasting experience. In fact, remembered or even imaged events can create emotional responses [12].

Tourism provide consumers a way to escape from their everyday, ordinary life and they will search for experiences that offer them fun, pleasure and a way to enact dreams and fantasies [13]. With respect to wine tourism, it offers the possibility of "indulging of the senses in the wine product itself and its immediate aesthetic surroundings" [14]. The wine tourist is fully immersed in the experience of pleasure. Furthermore, in the tourists' desire to live out dreams, he/she is more hedonistic, self-indulgent and pleasure-seeking [15]. The tourist or "vacation consumer" feels free of responsibility and constraint, moving away from functional products or rational consumption and more willing to buy based on their feeling, mood, and emotions.

\subsection{Wine tourism opportunities and challenges}

With the global boom in tourism in general, and wine tourism in particular, consumers now have a new way of connecting with wine and in a much more profound way: consuming it at its place of origin. Wine tourism offers the visitor (or consumer) a new and non-traditional retail space, different from the supermarket, wine shop or restaurant, a new physical surrounding - usually in a region outside their home, and close contact with the producer, be it the winemakers, the family or winery staff. This provides the visitor an intimate and dynamic encounter with the product and the brand, removing barriers and encouraging interaction. The consumer is fully immersed in the world of the brand.

This is a huge business opportunity, with many wineries offering wine tourism as a way to increase wine sales and for greater brand recognition and loyalty. It also provides a new channel to communicate directly with the end consumer, something that is unimaginable in most industries. However, wine tourism is complex and a multi-dimensional business, with various elements and touchpoints of interaction that affect the way the visitor feels [16] and connects with the brand. Thus, wine tourism poses challenges and requires careful planning, designing and implementation so that the visitor experience is exciting, stimulating and most importantly, memorable.

While wine tourism has evolved from showing people around the winery and cellars to creating sophisticated and high-quality experiences, there is one area that continues to be a challenge and mirrors the same challenge of the trade: wine communication.

Wine tourism scholars have not been able to provide a clear profile of who the wine tourist is, as this can vary depending on region, but most studies show that wine tourism does not attract a large portion of wine experts or connoisseurs $[17,18]$. The majority of winery visitors have little wine knowledge and are attracted by the dream of wine and the associations with the beverage, such as the lifestyle, the culture or heritage. The curiosity to understand how wine is made is just one motivating factor in visiting a winery. Their expectations from a wine experience is much more ample [18]; what they search for 
is a connection with the people, place and experiencing the product in a profound way.

Some wineries view wine tourism as simply a way to sell a few bottles [19], as a result they present wine in a technical way as if discussing to a professional. While educating visitors about the winemaking process is important, it is also important to find the right balance between educating, entertaining and stimulating the good feelings of the visitor. By overloading them with wine information, the visitor will tune out and disengage. By providing too little information they may feel unsatisfied, making it less likely to purchase wine [20]. Therefore, the communication or tour "script" must be adapted to the needs, interests and knowledge of the visitor, not just to increase visitor satisfaction, but also to create connections with the consumer. These are where the challenges lie, as well as the opportunities in wine tourism. If a winery is not able to provide something new, distinct and authentic that resonates with the visitor, then wine tourism becomes ineffective in its purpose and objectives.

\section{Storytelling and its emotional power}

It can be assumed that storytelling is used because it appeals to our very primitive nature, that is of sharing knowledge in an entertaining and digestible way. However, narratives are important for personal development as they serve various psychological purposes. Stories serve as a way for humans to understand the outer world but also explore their inner world; a way to learn or investigate the outer world, and also as a way to escape or forget the inner world. Stories can help to deal with identity issues, to heal or to cope with suffering. Further, most narratives are built from myths because they provide meaning and include other elements that guide humans, such as culture, religious, and social norms and structure [21]. In this way, stories provide a "map" on how to live in this world, making them incredibly important. The research done by mythologist Joseph Campbell demonstrates that humans, in their most civilized or primitive form, will find ways to tell stories in order to cope with threats, changes and the challenges of the experience of living [22]. It is also through stories that people find meaning and feel inspired "to reconnect with creativity, illumination, and imagination" [23].

We, as humans, are born to feel pleasure or displeasure, to feel good or bad. This state is known as core affect, and is the basis of emotions [24]. Core affect is influenced by stimuli or events in the environment, that allow us to evaluate situations or objects for personal relevance or for their value. Emotions do not occur merely on the psychological plane, but can be explained through neuroscience. Recent research in brain processing has revealed key insights into emotions and behavioral responses, particularly how engaging narrative can result in action or changes. Breakthrough research by neuroscientist Paul Zak (2005) found the correlation between the chemical hormone, oxytocin, and trust [25]. As the brain releases oxytocin, humans feel more trust with those around them and results in positive social interactions. His follow up studies then focused on narrative and the impact on oxytocin release. It was found that engaging narrative can be powerful enough to release oxytocin and thus, result in a feeling of empathy for the characters or protagonist of a story [26]. Empathy or emotional resonance can produce post-narrative actions, according to Zak's work. In his experiment, a touching story about a father who watched as his two-year-old son died of cancer resulted in participants donating money to charity. Thus, demonstrating the linkages between a compelling story and post-narrative actions.

Narrative does not need to be solely in written form, but can include watching or hearing a story. According to Zack, one key element that is required in storytelling for emotional resonance is transportation. Transportation occurs when the reader is mentally transported into the world of narrative and loses touch with the real world. When the brain is completely engaged, it stops scanning the external environment for perceived threats or other things of interest. With full attention on the story, transportation can be so intense that the reader/listener can go through a process of transformation, changing their beliefs or attitudes, by the experience of narrative [27]. If the audience has an affinity to the main character, then there is an increased chance to change feelings or beliefs that are in line with those of the character. The power of persuasion through storytelling requires a narrative that engages the brain. When this happens, the brain will even overlook contradictory or conflicting information, suspending belief for the purpose of enjoyment and pleasure [28]. Therefore, storytelling can be used to influence behavior and actions.

When we focus on storytelling as a marketing and communication technique, it can help create a connection with the consumer, building brand trust and develop consumer empathy. While a story can tap into the emotions of the consumer, brand authenticity and shared values have become increasingly important in the consumerbrand relationship [29]. Consumers choose brands for self-identification, those that reflect their identity or desired identity. They consume products or service for meaning and for a sense of belonging [30]. However, consumers have become more critical and they no longer look at the product being consumed but at the brand and how "real" or "true" it is. That is, how authentic it is. As a fluid concept, authenticity plays an important part in brand-consumer relationship and affects consumer's behavioral intentions [31]. Some studies found that authenticity can be influenced by identifiable variables, such as brand heritage, brand nostalgia, brand commercialization, brand clarity, brand's social commitment, brand legitimacy, and employee's passion [32]. Studies related to wine brand authenticity noted the following attributes: heritage and pedigree, stylistic consistency, quality commitments, relationship to place, method of production, and downplaying commercial motives [33]. The financial aspect is very important to note as "Consumers may judge a brand as authentic when the brand is perceived to be directed by individuals who are inherently interested in the products they produce and who are motivated by the gratification they feel when producing their products" [34]. Conversely, a brand is perceived to be inauthentic when it is managed by individuals who only focus on financial gain and are motivated by commercial ends. Authenticity is romanticized by the consumer, like an artist who creates for the purpose of fulfilment and does not compromise his/her views for commercial success [35]. Storytelling can capture brand authenticity in the form of 
brand biography. Brand narratives offer "multiple points of entry to forge identification with the people behind the brand and with the brand itself" [36] Storytelling not only serves to stir up the emotions of the consumer, but also as a means to communicate who the brand is, their values and how those relate to the consumer.

\subsection{Narrative structure}

We have seen that stories help consumers connect and identify with brands but a simple narrative is not enough to achieve the desired purpose of marketing which is to influence the consumer to purchase and repurchase and to stay loyal to the brand. The narrative must be mentally engaging and emotionally compelling, because "if the story does not sustain our attention, then the brain will look for something else more interesting to do" [37].

The brain recognizes a good story over a bad one [38], which is why following a story structure is not only important for literary effect but for persuasion. Zak's research highlighted the importance of sustained attention and emotional engagement with the characters of the story through neuroscience. Attention activates the hormone cortisol, signaling that there are potential threats in our environment. This is most evident in physical signs that include increased heart beat or sweaty palms. However, attention fluctuates during a story as the brain continuously scans the environment for more interesting or pressing matters. If the narrative is engaging enough, the brain is able to refocus and become transfixed, holding all attention and being completely transported into the narrative. The key to emotional resonance, states Zak, is attention. Emotional engagement results in greater bonding, connection and feeling of identification with the character and his/her struggle.

In order to create a narrative that sustains attention, several frameworks have been explored in literary fields. Perhaps the most recognizable story structure is the dramatic arc of German novelist Gustav Freytag. Freytag broke down the story into five parts: exposition, rising action, climax, falling action and denouement. This structure overlaps well with the work of Zak on narrative and chemical reactions, by keeping the brain engaged with events that lead up to the climax.

In the field of mythology, Campbell offers another framework that resonates with many cultures and is the basis of most myths, that of the Hero's Journey [39]. In mythological structure, the hero is called to action to obtain a prize or boon that can save the kingdom. The hero decides (or is forced) to leave the known world and enters the unknown, such as the forest. Throughout the journey, the hero undergoes a series of challenges or obstacles and must find the tools and determination to continue. During this process, the hero goes through a powerful transformation (either internal or externally) and once the hero obtains the prize, he/she can re-enter the known world, usually as a savior of the people.

Another framework that is frequently employed is the underdog narrative [40]. Popular in Western culture, the underdog narrative is powerful and is reflected in popculture such as in the films Rocky and Harry Potter, or in brand biographies such as Apple and Google. It is even the basis of the American Dream. Similar to Campbell's hero structure, the underdog must succeed and overcome obstacles and, has two key traits. One, the underdog is externally disadvantaged, either financially or physically, and two, the underdog has a strong character: passion and determination. The underdog starts with little or nothing at all and succeeds against all odds because of their will and hard work. Underdog stories are relatable to many consumers, even for those who are not underdogs themselves but perceive themselves to be. Further, the underdog story has a greater effect for products that have social identity functions, symbolic meaning and when product is intended for public usage.

In summary, a good story has a way of stirring our emotions, awakening our imagination and transporting us to another world. Stories and myths have also been the foundation of human communication, serving as a way to understand our world. In marketing, stories function as a powerful tool for brand messaging and to strengthen consumer-brand relationships. It is no wonder then that the famous writer, Margaret Atwood, once commented, "You're never going to kill storytelling, because it's built into the human plan. We come with it" [41]

\section{Case study: Quinta do Vallado}

Quinta do Vallado is a historic winery located in the Douro Valley in northern Portugal. Comprising of two beautiful properties, one near the town of Peso de Regua, in the Baixo Corgo (Lower Corgo) sub-region and the second in the Douro Superior (Upper Douro), 70 hectares and 30 hectares of vineyards respectively, the winery produces both Port wine and still wine. Founded in 1716, it is one of the oldest wine estates in the Douro and is considered one of the most prestigious, wining various international awards and accolades. Quinta do Vallado is also famous for the winery's architectural design, a modern, gravityflow winery using local material (schist rock).

Quinta do Vallado currently offers wine tourism experiences, which includes hotel and accommodations at both properties, and tour and tastings at the winery in Regua. Because of an increase in wine tourism in Portugal and the Douro in particular, and considering Vallado's reputation and excellent location in the Douro, the winery was overwhelmed by visitors. Thus, Vallado underwent a total makeover of its wine tourism services to accommodate for the influx of visitors. This included redesigning the tour and tasting, and using storytelling as a way of communicating the brand story for greater visitor engagement.

\subsection{Evaluation of wine tour script}

The first step was to evaluate the tour and tasting which was completed by the author in collaboration with DMC, Catavino. The evaluation revealed that the length of the visit was too long and it revealed two other key issues: a fragmented tour route and a "traditional" script to accompany it.

The fragmented route caused the most problems in terms of timing and flow. The route followed the path of wine from vine to bottle, but due to the winery's size, the visitor path jumped from one space or building to another through various corridors and stairways. To solve this issue, a new route was designed, one which was focused on highlighting areas of particular attractiveness in the 
winery, both in terms of aesthetic and uniqueness, and also removing stops that were unappealing or made travelling difficult. In addition, the new route no longer followed a linear journey of winemaking, but instead a route based on the narrative (see below) from past to present, from the old Port cellar to the modern barrel cellar.

The second issue that surfaced through the evaluation was related to the content and quality of the tour script. The script is vital to the wine experience because it the channel through which the brand information is passed to the visitor. The script that was used to accompany the visit relied heavily on winemaking concepts and processes that, while thorough, it was not unique from other winery tours. A previous study by the author [42], which involved evaluating winery tours and experiences in Portugal, demonstrated that very few wineries had developed a unique script and story for the winery tour. The overwhelming majority of wineries only discussed technical aspects and left no memorable impression. The Vallado script was no different; it did little to engage the imagination and the emotions of the visitor and also had very little emphasis on the Vallado brand story.

It is important to note that the script in the tourism context serves as a supporting tool for guides to communicate the most important information and to deliver the brand message. Because wine tourism is interactive, the script is not intended to be recited or used as in a theatrical performance. It can and must be adapted by the guide for the audience and their interests. The script is a powerful communication tool and should not be overlooked when designing a wine tour or experience.

\subsection{Changing the script to a compelling story}

The process of changing the script was three-fold. First, it required analyzing the existing script, determining what information was vital and what was unnecessary. The next step required researching Vallado's archives to find a real story from the company history that could be told to the visitor. The final step was drafting a script that included all of the following: a compelling story, winemaking and relevant wine educational information and transmitting the Vallado message. This script also needed to be designed to fit in with the new, shortened tour route.

\subsubsection{Analysing the script}

The original Vallado written script was 10 pages long and contained a great deal of technical wine terminology, figures, temperatures, weights and other facts related solely to winemaking. However, the names of the important characters in Vallado's history were scarcely mentioned. For instance, Dona Antonia Adelaide Ferreira, the founder, was only referred to once and three times by her nickname ("Ferreirinha"), the winery architect was mentioned once, and the name "Quinta do Vallado" was referred to twice. The name of the current owners was not included at all in the script.

The analysis revealed that the script was suitable for high-involvement wine visitors and professionals. It was also effective as a training resource and to answer technical questions. However, for general tourists, there was a real risk of overloading and overwhelming them with winemaking information. Further, there was no point of differentiation in the script; the visitor would hear a script that was similar to most other wineries but no real connection to Vallado. There was no takeaway message about the Vallado brand, values and overall importance. The visitor would leave not knowing who or what was Vallado nor what made them special. Further, the lack of hearing the name Vallado spoken by the guide also meant that the winery name would be easily and quickly forgotten once the visitor had left the premise.

\subsubsection{Finding a compelling story: Deconstructing the narrative}

The next stage was finding a unique story that would embody the Vallado spirit and would work with their brand personality. The research into the Vallado history revealed an important character that was only briefly mentioned in the original script, Dona Antonia Adelaide Ferreira. Dona Antonia was owner of Quinta do Vallado and the winery has stayed within the same family since her death. She was one of the most powerful women in wine in the 1800s, being the first woman wine entrepreneur in Portugal. To this day, she is a well-respected and a beloved figure in Douro region, yet tourists and outsiders hear very little about her life and her legacy.

By exploring further into her life with the winery's archivist, we found a relatable and courageous protagonist that would resonate with visitors: a young woman, a widow and single mother and an entrepreneur. Her life story was not without difficulties and challenges, and her love for the land, wine, as well as her compassion to workers provide many emotional elements. She also clearly represented the innovative and progressive spirit of Vallado.

As we constructed the narrative, we needed to deconstruct the character for emotional resonance. For example, we asked these questions: why is this character important to our story, how is she relatable (the underdog or the hero or both?), how is she relatable to female or male visitors, what are her strengths, her weaknesses? How do those traits help move the story along? How does she change over the course of the story?

We deconstructed other elements of the story, such as the events in the story: what are her challenges, her successes, and her failures? Are these relatable and relevant to today's audience? Are the events compelling and able to maintain engagement? Is the climax of the story powerful enough?

We also needed a secondary narrative, one that would tell the modern history of Vallado. Vallado itself is a very young company, founded in 1987, and when visiting the winery, you will see a modern gravity winery with impressive architecture. Thus, the story of Dona Antonia would not be entirely suitable. A new story also needed to get told, a new story for the new generation. Through various interviews with the current owners, who are direct descendants of Dona Antonia, there was another compelling story: the story of two cousins who had a dream of making still wine in a Port wine region. We repeated the deconstruction process of these new characters, their relatability, their challenges and obstacles, motives and the series of events that unfold until the climax of their story. 


\subsubsection{A script suitable for the winery tour}

The next stage was to take the Vallado stories, theme, characters, and events and write a script that would fit with the stops during the tour. The winemaking process also needed to be weaved into the script, providing the educational portion.

The tour was redesigned and that allowed us to develop a story chronologically, starting at the Port cellar with the story of Dona Antonia. She is the protagonist of the story, and the visitor is introduced to her, finding out how she was called on to her "heroine's journey" when her husband died and she was left widowed. While in the Port cellar, the foundation and scene of the story are set: the development of the Port wine industry and the background context of Dona Antonia' story are further explained. Our heroine is faced with ongoing challenges, particularly being a woman in a man's world, a wine world controlled by foreigners. The next stop takes the visitors to the vineyards, at a small lookout point that faces the Corgo River giving way to incredible views of the vineyards and terraces. At this stage of the story, the visitor is asked to imagine what the hills and valley would have looked like without the rows of vines, completely abandoned. It is here that the visitor hears how vine diseases, particularly phylloxera, caused the entire industry to fall to its knees and resulted in many farmers leaving their homes and vineyards. Our heroine, Dona Antonia Ferreira, who has an undying love for the Douro, is determined to overcome this challenge and keep her compatriots from leaving.

The visitor then makes their way into the barrel cellar. At this stop, the visitor hears the climax of Dona Antonia's story, which transitions into the story of the new generation, that is of Quinta do Vallado under its own name. Here, the Vallado story and brand values are heard in greater detail. The modern barrel cellar serves as a parallel with modern winemaking techniques that have been adopted by the Vallado owners, and the belief in making quality still, unfortified wines in addition to Port wines.

The final stop is in the tasting room, where the visitor can relax and taste wine. Here, the tasting also takes on part of the narrative. With each wine tasted, the visitor learns about the challenges that the owners of Vallado had to overcome, such facing a very traditional wine industry and getting international recognition. With the final wine that is served, a Port wine, the visitor comes full circle in their emotional journey. And so, the wine tells a story beyond the product itself and the Vallado brand is not just a brand but a story to remember and tell.

\section{Limitations and future implications}

The new tour and script were created to make the winery tour engaging, emotional and imaginative. While this case study briefly describes the ideas behind the narrative and the tour, other touristic elements were not discussed here but are important to the overall experience, such as the use of props, infographics, handheld brochures and audiovisual material that emphasize parts of the narrative and enhance the sensory experience. Of particular importance to storytelling is the role of the tour guide as the storyteller, which was not discussed in this paper but deserves attention. The delivery of the script, communication and interaction with visitors have great impact on the experience and the effectiveness of storytelling [43]. Beyond these factors, time is also required to monitor and evaluate the effectiveness of the tour and script. Revisions and adjustments based on staff and visitor feedback will be required. Wine tourism is not static. As a result, constant evaluation and alterations are part of this business.

The use of storytelling can be effective as a communication technique but brand narratives must be used with caution for global audiences [44]. Each culture has different local values, myths and cultural beliefs and narrative should be adapted to the culture of consumers. For instance, the underdog story is powerful to Westerners but it may not necessarily resonate as strongly with Asian audiences or other non-western cultural audiences.

\section{Conclusion}

Currently, there are no wine tourism papers or studies that have focused on the script and storytelling of the tour. What this study has presented is a new approach to the winery tour communication and how the script is integral to the experience. The use of storytelling during a winery visit not only enhances the visitor experience but also imprints into the consumer's mind more than winemaking processes.

Stories help consumers connect and identify with brands. Through the effective use of narrative structures, such as the hero's journey or the underdog framework, and the literary elements to develop a good story, such as the use of theme, plot, climax, and relatable characters, allows the audience to transport themselves into the narrative and make them empathize with the characters. Neuroscience informs us that a compelling narrative permits the release of brain chemicals, specifically cortisol and oxytocin, which result in sustaining attention, empathy and behavioral responses. Conversely, a story without developing a compelling narrative will end up as a dry exposition of facts. While hard facts may be interesting momentarily, they will not make impact or leave a durable imprint on the consumer. Thus, the power of persuasion through storytelling requires a narrative that engages the brain.

In conclusion, storytelling provides the missing link needed to engage the consumer on another plane, the emotional one. It is through this emotional engagement that the visit and brand become memorable. After all, who does not love a good story?

\section{References}

[1] OIV 2018, Rept World Vitiviniculture Situation

[2] Wine Intelligence Press Release: US Millennials Turning Away from Wine Amid Decreasing Frequency of Wine Consumption (2019)

[3] S. Platania, G. Santisi, Wine Eco. Policy 5, 87 (2016)

[4] J. Lawrence, "The Maddening Business of Marketing to Millennials" Retrieved from https://www.winesearcher.com $/ \mathrm{m} / 2019 / 03 /$ the-maddening-businessof-marketing-to-millennials (2019)

[5] A. Patterson, S. Brown, The Mktg. Rvw. 5, 315 (2005) 
[6] D. Vigar-Ellis, L. Pitt, P. Berthon, Bus. Hzns. 58, 679 (2015)

[7] S. Platania, G. Santisi, Wine Eco. Policy 5, 87 (2016)

[8] S. Mueller, G. Szolnoki, Food Qty. Pref. 21, 774 (2010)

[9] S. Platania, G. Santisi, Wine Eco. Policy 5, 87 (2016)

[10] M. Holbrook, E. Hirschman, J. Cons. Res. 9, 132 (1982)

[11] H. Wolf, S. Morrish, "This Is My Perfect Match! Understanding Luxury Wine Consumption" from http: //academyof winebusiness . com/wpcontent/uploads/2016/03/49. -THIS-IS-MYPERFECT-MATCH-UNDERSTANDING-LUXURY-WINECONSUMPTION . pdf (2016)

[12] R. Ferrarini, C. Carbognin, EM. Casarotti, E. Nicolis, E. Nencini, A.M. Meneghini, Food Qty. Pref. 21, 720 (201)

[13] C. Hening, The Tourist as a Metaphor of the Social World 169 (2002)

[14] J. Bruwer, K. Alant, Int. J. Wine Bus. Res. 21, 235 (2009)

[15] N. Wang, The Tourist as a Metaphor of the Social World 281 (2002)

[16] J. Carlsen, P. Boksberger, J. Hspty. Trsm. Res. 39, $132(2015)$

[17] S. Charters, J. Ali-Knight, Trsm. Mgmt. 23, 311 (2002)

[18] E. Byrd, B. Canziani Y. Hsieh, K. Debbage, S. Sonmez, Trsm Mgmt. 52, 19 (2016)

[19] J. Carlsen, P. Boksberger, J. Hspty. Trsm. Res. 39, $132(2015)$

[20] D. Vigar-Ellis, L. Pitt, P. Berthon, Bus. Hzns. 58, 679 (2015)

[21] T. Van Laer, L. Visconti, S. Feiereisen, J. Mktg. Mgmt. 34, 484 (2018)

[22] Campbell, Joseph, The Hero with a Thousand Faces. (Princeton University Press, 1949)

[23] T. Van Laer, L. Visconti, S. Feiereisen, J. Mktg. Mgmt. 34, 484 (2018)
[24] L.F. Barrett, B. Mesquita, K.N. Ochsner, J.J. Gross, Annu. Rev. Psychol. 58, 373 (2007)

[25] M. Kosfeld, M. Heinrichs, P. Zak, U. Fischbacher, E. Fehr, Nature 435, 673 (2005)

[26] P.J. Zak, Cerebrum: The Dana Forum on Brain Science 2 (2015)

[27] M. Green, T. Brock, J. Persnty, Social Psy. 79, 701 (2000)

[28] P.J. Zak, Cerebrum: The Dana Forum on Brain Science 2 (2015)

[29] N. Paharia, A. Keinan, J. Avery, J. Schor, J. Cons. Res. 37, 775 (2011)

[30] P. Mora, J. Moscarola, Intl. J. Cons. Stud. 34, 674 (2010)

[31] K. Fritz, Euro. J. Mktg. 51, 324 (2016)

[32] Ibid

[33] M. Beverland, J. Bus. Res. 59, 251 (2006)

[34] J. Moulard, R. Raggio, J. Garretson Folse, Psychol. Mktg. 33, 421 (2016)

[35] Ibid

[36] N. Paharia, A. Keinan, J. Avery, J. Schor, J. Cons. Res. 37, 790 (2011)

[37] P.J. Zak, Cerebrum: The Dana Forum on Brain Science, 2 (2015)

[38] Ibid

[39] C. Joseph, The Hero With a Thousand Faces. (Princeton University Press, 1949)

[40] N. Paharia, A. Keinan, J. Avery, J. Schor, J. Cons. Res. 37, 775 (2011)

[41] L. Rothman, Margaret Atwood on Serial Fiction and the Future of the Book Retrieved from http://entertainment.time.com/2012/10/08/ margaret-atwood-on-serial-fiction-andthe-future-of-the-book/ (2012)

[42] V. Woldarsky, L. Geny-Denis, BIO Web of Conf. 12, 03001 (2019)

[43] J. Ap, K. Wong, Trsm Mgmt 22, 551 (2001)

[44] N. Paharia, A. Keinan, J. Avery, J. Schor, J. Cons. Res. 37, 775 (2011) 